\title{
Spectrum of Clinical and Hematological Changes in Patients of Malaria: A Tertiary Care Hospital Experience in Gujarat
}

\author{
Trupti R. Jansari ${ }^{1}$, Jigna P. Patel ${ }^{1}$, Amit Chauhan ${ }^{2}$, Jasmin Jasani ${ }^{3}$ \\ ${ }^{1}$ Assistant Professor, Department of Pathology, Smt BK Shah Medical Institute \& Research Centre, Sumandeep \\ Vidyapeeth an institution deemed to be University Piparia 391760 Vadodara Gujarat, ${ }^{2}$ Associate Professor, \\ Department of Anesthesia, Smt BK Shah Medical Institute \& Research Centre, Sumandeep Vidyapeeth an \\ institution deemed to be University Piparia 391760 Vadodara Gujarat, ${ }^{3}$ Professor, Department of Pathology, Smt \\ BK Shah Medical Institute \& Research Centre, Sumandeep Vidyapeeth an institution deemed to be University \\ Piparia 391760 Vadodara Gujarat.
}

\begin{abstract}
Background: One of the most common infections caused by protozoa in India is malaria. Malaria cases have different geographic distribution in different areas. So it is important that hospitals in different areas draw their own set of data regarding clinical and hematological characteristics of malaria. The present study was conducted to evaluate the spectrum of clinical and hematological changes in patients of malaria.

Material and method: We conducted retrospective study at Pathology department, Sumandeepvidyapeeth, with 55 patients aged between 5 to 75 years.

Results: Out of 55, 40 were males and 15 were females. PV constituted majority of the cases, followed by PF. We reported anemia in 34 of malaria cases. Maximum cases of anemia was seen in PF. Thrombocytopenia was seen in 42 of malaria cases. Maximum cases was seen in PV. Leucocyte count was within reference range in majority of our cases 42 .

Conclusion: Fever with rigors and chills, headache and splenomegaly are the most common clinical alteration and anemia and thrombocytopenia are most common hematological alteration in cases of malaria. Presence of these classic picture in a patient ever, helps diagnosing malaria at the earlier stages. In that way, early treatment can be introduced.
\end{abstract}

Keywords: Anemia, Fever, Malaria,Plasmodium falciparum, Thrombocytopenia.

\section{Introduction}

One of the most common infections caused by protozoa in India is malaria. There are five different species of plasmodium (P.) that are responsible for malaria

\section{Corresponding Author:}

\section{Dr. Jigna P Patel}

Assistant Professor, Department of Pathology, Smt BK Shah Medical Institute \& Research Centre, Sumandeep Vidyapeeth an Institution Deemed to be University Piparia 391760 Vadodara Gujarat e-mail: creativity.art.j@gmail.com Mobile No.: +91-9727079195 infection in humans. These are Plasmodiumfalciparum (PF), Plasmodium vivax (PV), Plasmodiumovale, Plasmodiummalariae and Plasmodiumknowlesi. A bitefron infected female Anopheles type of mosquito is the main route of transmission. Other routes are via blood transfusion, marrow transplants and across the placenta. Causative agent of severe and complicated malaria is usually PF. Other species causes usually mild disease. ${ }^{[1]}$ Although there is continuous ongoing work to decrease the number of case by various means, malaria still remains the most common protozoan infection in developing countries. [2] World health organization report states that $6 \%$ of the cases all over the world are detected in India. ${ }^{[3]}$ 
Most common clinical features of malaria are fever which is intermittent and high grade in nature, rigors and chills, headache, nausea and vomiting. ${ }^{[4]}$ There are certain characteristic hematological changes that are attributed to malaria and commonly seen among malaria patients. Some of the common findings are anemia, thrombocytopenia, leucopenia and splenomegaly. [5-7] The present study was carried out to have insight into the clinical and hematological spectrum of changes in patients of malaria in Gujarat.

\section{Material and Method}

We conducted this retrospective study at Hematologylaboratory, Pathology department, Sumandeepvidyapeeth, Vadodara. We included total 55 patients aged between 5 to 75 years with either gender. Details regarding demographic, clinical and laboratory investigations of each patients were noted. Patients below 5 years and more than 75 years were excluded from the study. Two mililitres blood was collected in EDTA vaccuttee and processed oncell counter SYSMEX KX-21. All hematological report details were noted. We prepared blood films for both thick and thin smears as per the standard protocols and were processed further with giemsa stain and leishman cytochrome stain. A positive diagnosis of malaria was confirmed by pathologist after examination of thick and thin smear. Malaria species identification was done for different species. We called the patient has an anemia when the hemoglobin $(\mathrm{Hb})$ was less than $13 \mathrm{~g} / \mathrm{dl}$ in a male patient and less than $12 \mathrm{~g} /$ $\mathrm{dl}$ in a female patient. Thrombocytopenia was diagnosed when the platelet count was less than 1.5 lacs/cumm. Leucopenia and leucocytosis when total leucocyte count(TLC) was less than 4000 cells/cumm and more than 11000 cells/cumm respectively. We used Epi info software for calculating various statistics.

\section{Results}

We conducted this retrospective study at Hematologylaboratory, Pathology department, Sumandeepvidyapeeth, Vadodara. We included total 55 patients aged between 5 to 75 years with either gender. Details regarding demographic, clinical and laboratory investigations of each patients were noted.

There were total 55 cases of malaria, $40(72.7 \%)$ were males and $15(27.3 \%)$ were females. We found male preponderance of the disease. (Table - 1) Male to female ratio in our study was found to be 2.6:1.

Table 1. Gender wise distribution of the cases

\begin{tabular}{|l|c|c|}
\hline Gender & Cases & Percentage (\%) \\
\hline Male & 40 & 72.7 \\
\hline Female & 15 & 27.3 \\
\hline Total & $\mathbf{5 5}$ & $\mathbf{1 0 0}$ \\
\hline
\end{tabular}

We divided the cases into 3 groups as per species identification. (Table - 2) Highest numbers were of PV 41(74.5\%), followed by PF 12(21.8\%) and mixed infection $2(3.6 \%)$ type.

Table 2. Distribution of cases as per the malaria species identification

\begin{tabular}{|l|c|c|}
\hline Malaria Species & No of Cases & Percentage \\
\hline P. Falciparum & 12 & $21.8 \%$ \\
\hline P. Vivax & 41 & $74.5 \%$ \\
\hline Mixed Infection & 02 & $3.6 \%$ \\
\hline Total & $\mathbf{5 5}$ & $\mathbf{1 0 0 \%}$ \\
\hline
\end{tabular}

We evaluated clinical data of all the cases of malaria. Fever was seen in all the cases 55(100\%). Apart from fever, the most common clinical features were rigors and chills 34(61.8\%) followed by headache 26(47.2\%), nausea and vomiting 20(36.3\%) and splenomegaly $28(50.9 \%)$ (Figure 1 ). 


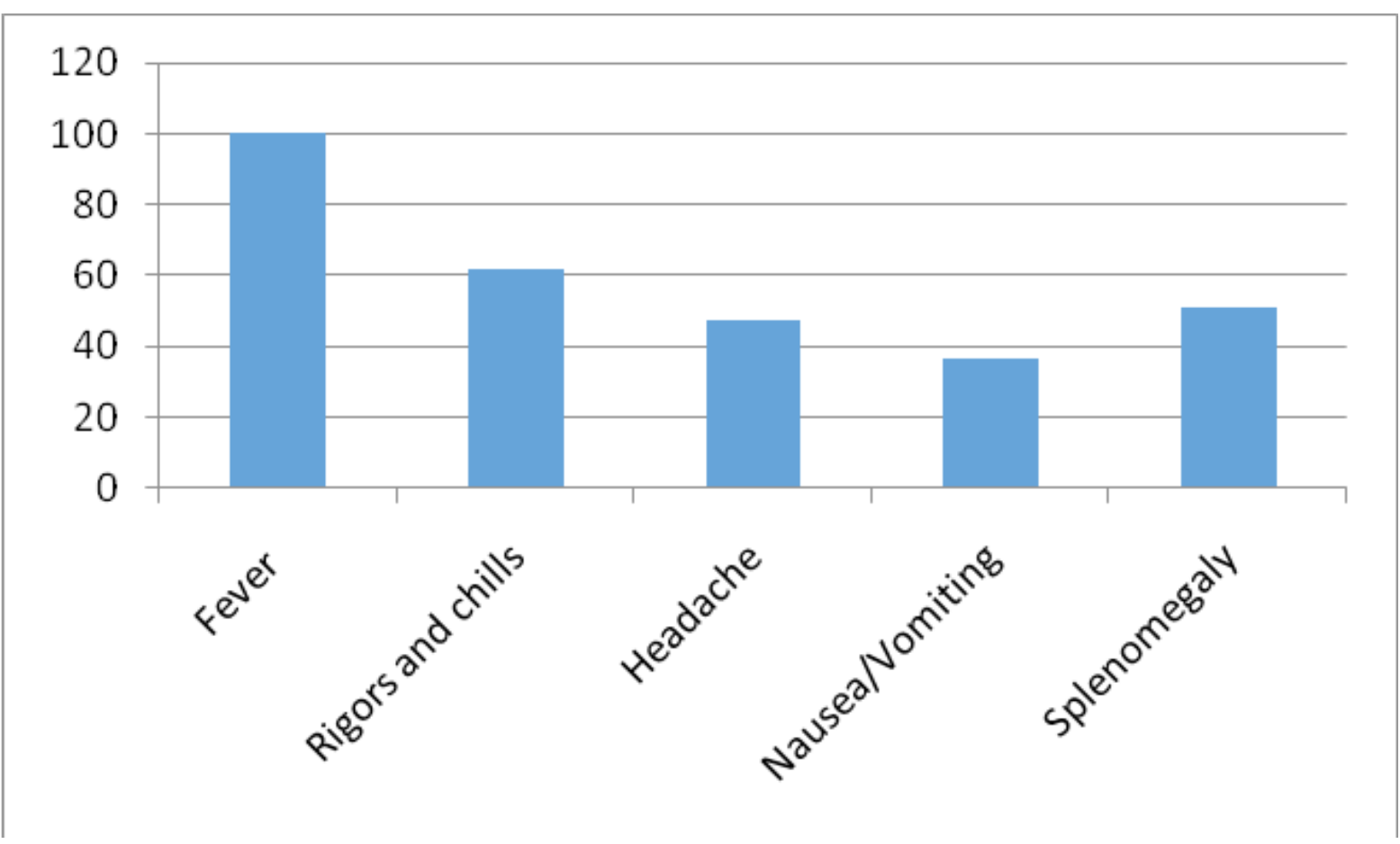

Figure 1. Distribution of cases as per the clinical features

We found anemia in 34(61.8\%) of malaria cases. Other 21(38.2\%) cases had normal hemoglobin levels. Out of these 34 cases maximum cases of anemia was seen in PF 11(91.6\%), followed by PV 22(53.6\%) and mixed infection 01(50\%). (Table 3).

Table 3. Distribution of anemia cases in different types of malaria

\begin{tabular}{|l|c|c|c|}
\hline Type of Malaria & Cases with Anemia & Cases With Normal Hemoglobin & Total \\
\hline P. Falciparum & $11(91.6 \%)$ & $01(8.3 \%)$ & $12(21.8 \%)$ \\
\hline P. Vivax & $22(53.6 \%)$ & $19(46.3 \%)$ & $41(74.5 \%)$ \\
\hline Mixed Infction & $01(50 \%)$ & $01(50 \%)$ & $2(3.6 \%)$ \\
\hline Total & $\mathbf{3 4}(\mathbf{6 1 . 8 \% )}$ & $\mathbf{2 1 ( 3 8 . 2 \% )}$ & $\mathbf{5 5}(\mathbf{1 0 0} \%)$ \\
\hline
\end{tabular}

We found thrombocytopenia in $42(76.4 \%)$ of malaria cases. Other $13(23.6 \%)$ cases had normal platelet counts. Out of these 42 cases maximum cases of thrombocytopenia was seen in PV 31(75.6\%), followed by PF 9(75\%) and mixed infection $0(0 \%)$. (Table 4$)$.

Table 4. Distribution of thrombocytopenia cases in different types of malaria

\begin{tabular}{|l|c|c|c|}
\hline Type of Malaria & Cases with Thrombocytopenia & Cases With Normal Platelet Count & Total \\
\hline P. Falciparum & $9(75 \%)$ & $03(25 \%)$ & $12(21.8 \%)$ \\
\hline P. Vivax & $31(75.6 \%)$ & $10(24.3 \%)$ & $41(74.5 \%)$ \\
\hline Mixed Infction & $0(0 \%)$ & $02(100 \%)$ & $2(3.6 \%)$ \\
\hline Total & $\mathbf{4 2 ( 7 6 . 4 \% )}$ & $\mathbf{1 3}(\mathbf{2 3 . 6 \% )}$ & $\mathbf{5 5 ( 1 0 0 \% )}$ \\
\hline
\end{tabular}

In our study, maximum cases had leucocyte count within normal reference range e.g 42(76.4\%). Leucocytosis was present in $8(14.5 \%)$ and leucopenia in $5(9.1 \%)$ cases. Out of these, PF showed higher number of leucocytosi (8.3\%), while PV showed higher cases of leucopenia, while both the cases of mixed infection showed normal TLC. (Table 5). 
Table 5. Distribution of leucocytosis and leucopenia cases in different types of malaria

\begin{tabular}{|l|c|c|c|c|}
\hline Type of Malaria & Cases with Leucocytosis & Cases With Leucopenia & Cases With Normal Tlc & Total \\
\hline P. Falciparum & $1(8.3 \%)$ & $1(8.3 \%)$ & $10(83.3 \%)$ & $12(21.8 \%)$ \\
\hline P. Vivax & $1(2.4 \%)$ & $4(9.8 \%)$ & $36(87.8 \%)$ & $41(74.5 \%)$ \\
\hline Mixed Infction & $0(0 \%)$ & $0(0 \%)$ & $02(100 \%)$ & $2(3.6 \%)$ \\
\hline Total & $8(14.5 \%)$ & $5(9.1 \%)$ & $42(76.4 \%)$. & $55(100 \%)$ \\
\hline
\end{tabular}

\section{Discussion}

The present retrospective study included total 55 patients with age ranging from 5 years to 75 years. There was male preponderance in our study with male to female ratio of 2.6:1. This finding was comparable with many other studies carried out previously [4, 8-9] This can be due to increased exposure to males attributed to their more outdoor work as compared to females in some areas. In this study, there was maximum number of cases of PV type of malaria. Many other studies also showed the similar findings. ${ }^{[8-10]}$

In our study, fever was seen in all cases 55(100\%). Apart from fever, the most common clinical features were rigors and chills 34(61.8\%) followed by headache 26(47.2\%), nausea and vomiting 20(36.3\%) and splenomegaly 28(50.9\%). These findings were comparable to the study done by Chaudry et el. ${ }^{[8]}$

The most frequent finding in malaria is anemia. It can result from combination of many etiological factors. Eg. Lysis of infected red blood cells, bone marrow inefficiency, splenomegaly etc. Total $34(61.8 \%)$ patients out of 55(100\%) patients presented with anemia in our study. Whis is comparable to the previous literatures. ${ }^{[4]}$ Study done by Chaudry et el., Awoke $\mathrm{N}$ et al. and Abro $\mathrm{AH}$ et al. showed maximum cases of anemia in PF cases as compared to other types of malaria. We found the similar results in our study. ${ }^{[8,11-12]}$

Thrombocytopenia is very common hematological change that is seen in malaria. These can be due to various reasons. Eg. immunological mechanism, splenomegaly, or bone marrow inefficiency. We found thrombocytopenia in $42(76.4 \%)$ of total malaria cases. These results are comparable to that of the studies done by Abro AH et al., Jojera et al and Haroon et al. [12-14] Our study showed maximum cases of thrombocytopenia in PV 31(75.6\%) as compared to PF 9(75\%) and mixed infection $0(0 \%)$. These findings were comparable to that of the study done by Chaudry et el. ${ }^{[8]}$
Majority of the cases in our study showed leucocyte count within normal reference range e.g 42(76.4\%). Leucocytosis was present in $8(14.5 \%)$ and leucopenia in $5(9.1 \%)$ cases. These findings are similar to previous published literature. ${ }^{[4,8-9]}$ Leucopenia in malaria can be attributed to various theories e.g. immune mediated, low cell life, cell migration, increased inflammation, sequestration, bone marrow inefficiency etc. Study done by Abro AH et al. showed leucopenia to be more associated with PV than PF cases. We found the similar results in our study. ${ }^{[12]}$

\section{Conclusion}

High prevalence of malaria indicates importance of its timely diagnosis and treatment. Presence of classic clinical and hematological picture in a patient with fever, helps diagnosing malaria at the earlier stages. In that way, early treatment can be introduced and mortality occurring as a consequence of complicated cases on long run can be prevented.

Ethical Clearance: Ethical clearance was taken from SBKS \& MIRC

\section{Source of Funding: Self}

\section{Conflict of Interest: Nil}

\section{References}

1. Bates I, Ekem I. Haematological aspects of tropical diseases. In: Hoffbrand AV, Catovsky D, Tuddenham EGD, editors. Postgraduate Haematology. Massachusetts: Blackwell Publishing; 2005. p. 979-85.

2. WHO. World Health Director General's Report. Fighting disease, fostering development. Geneva: WHO, 1996.

3. World malaria report 2017.Geneva: World Health Organization; 2017.

4. Bashawri LAM, Mandil AA, Bahnassy AA, Ahmed 
MA. Malaria: hematological aspects. Ann Saudi Med 2002; 22:372-7.

5. Facer CA. Hematological aspects of malaria. In: Infection and Hematology. Oxford: Butterworth Heinmann Ltd., 1994:259-94.

6. PerrinLH,MackeyLJ,MiescherPA.Thehematology of malaria in man. Sem Hematol1982;19:70-81.

7. McKenzie FE, Prudhomme W, Magill A, et al. White blood cell counts and malaria. J Infect Dis.2005;192:323-30.

8. Chaudry JZ, Mahmood K, Hussain MA, Tahirkheli MUI. Spectrum of Clinical and Haematological Findings in Malaria. Gomal J Med Sci 2015; 13:100-3.

9. Shah N, Sinha R. A descriptive study of hematological characteristics of malaria patients attending a tertiary care hospital in the region of kutch. APALM; Vol - 6, Issue 10,Oct 2019, pg 531-536.
10. Gupta NK, Bansal SB, Jain UC, Sahare K. Study of thrombocytopenia in patients of malaria. Tropical Parasitology.2013;3:58-61.

11. Awoke N, Arota A. Profiles of hematological parameters in Plasmodium falciparum and Plasmodium vivax malaria patients attending Tercha General Hospital, Dawuro Zone, South Ethiopia.

12. AbroAH,UstadiAM,YounisNJ,AbdouAS,Hame dDA. Malaria and hematological changes. Pak J Med Sci.2008;24:287-91.

13. Jojera AS, Hathila RN, Patel PR, Tailor HJ. Changes in WBC and platelet count in patients with malaria: a hospital based comparative study. IntJ Res Med Sci 2013; 1(4):401-3.

14. Haroon H, Fazel PA, Naeem M, Mobin A, Naqvi AH, Makki K. Hide and seek: hematological aspects of malaria - a developing country perspective. J Infect Dev Ctries 2013; 7:273-9. 